\title{
Chronic Activation of the Relaxin-3 Receptor (RXFP3) on GABA Neurons in Rat Ventral Hippocampus Promotes Anxiety and Social Avoidance
}

Short running title: RXFP3 in ventral hippocampus promotes anxiety and social avoidance

Valeria Rytova ${ }^{1,2}$, Despina E. Ganella ${ }^{1}$, David Hawkes ${ }^{1, *}$, Ross A.D. Bathgate ${ }^{1,3}$, Sherie $\mathrm{Ma}^{1,2, * *, \dagger}$, and Andrew L. Gundlach ${ }^{1,2,4, \dagger}$

${ }^{1}$ The Florey Institute of Neuroscience and Mental Health, Parkville, Victoria, Australia

${ }^{2}$ Florey Department of Neuroscience and Mental Health, The University of Melbourne, Victoria, Australia

${ }^{3}$ Department of Biochemistry and Molecular Biology, The University of Melbourne, Victoria, Australia

${ }^{4}$ Department of Anatomy and Neuroscience, The University of Melbourne, Victoria, Australia

* Present Address: Department of Molecular Biology and Biochemistry, Victorian Cytology Service, Melbourne, Victoria, Australia.

** Present Address: Drug Discovery Biology, Monash Institute of Pharmaceutical Sciences, Monash University, Parkville, Victoria, Australia.

† These authors jointly supervised this research

\section{Correspondence:}

Andrew L. Gundlach, PhD

The Florey Institute of Neuroscience and Mental Health

30 Royal Parade, Parkville, Victoria 3052, Australia

Email: andrew.gundlach@florey.edu.au

Phone: +61 39035 6507, Mobile: +61 410746454

\section{Acknowledgments:}

This research was supported by the National Health and Medical Research Council of Australia (project grants 1005988 and 1067522 to ALG and RADB; senior research fellowships 1005985 and 1042650 to ALG and RADB, respectively); the Brain and Behavior Research Foundation (USA)

This is the author manuscript accepted for publication and has undergone full peer review but has not been through the copyediting, typesetting, pagination and proofreading process, which may lead to differences between this version and the Version of Record. Please cite this article as doi: 10.1002/hipo.23089

This article is protected by copyright. All rights reserved. 
NARSAD Independent Investigator Award (ALG), the Dorothy Levien Foundation (ALG); the Sir Edward 'Weary' Dunlop Medical Research Foundation (ALG); a Melbourne International Fee Remission and Melbourne Research Scholarship (VR); the Victorian Government Operational Infrastructure Support Programme (The Florey Institute of Neuroscience and Mental Health); and Pozible Crowd-Funding (https://pozible.com/project/34853). 


\begin{abstract}
Anxiety disorders are highly prevalent in modern society and better treatments are urgently required. Key brain areas and signalling systems underlying anxiety include prefrontal cortex, hippocampus, and amygdala, and monoaminergic and peptidergic systems, respectively. Hindbrain GABAergic projection neurons that express the peptide, relaxin-3, broadly innervate the forebrain, particularly the septum and hippocampus, and relaxin-3 acts via a $\mathrm{G}_{\mathrm{i} / \mathrm{o}}$-protein-coupled receptor known as the 'relaxinfamily peptide 3 receptor' (RXFP3). Thus, relaxin-3/RXFP3 signalling is implicated in modulation of arousal, motivation, mood, memory and anxiety. Ventral hippocampus (vHip) is central to affective and cognitive processing and displays a high density of relaxin-3-positive nerve fibres and RXFP3 binding sites, but the identity of target neurons and associated effects on behaviour are unknown. Therefore, in adult, male rats, we assessed the neurochemical nature of hippocampal RXFP3 mRNAexpressing neurons and anxiety-like and social behaviour following chronic RXFP3 activation in vHip by viral vector expression of an RXFP3-selective agonist peptide, R3/I5. RXFP3 mRNA detected by fluorescent in situ hybridisation was topographically distributed across the hippocampus in somatostatin- and parvalbumin-mRNA expressing GABA neurons. Chronic RXFP3 activation in vHip increased anxiety-like behaviour in the light-dark box and elevated-plus maze, but not the large openfield test, and reduced social interaction with a conspecific stranger. Our data reveal 'disruptive' effects of persistent RXFP3 signalling on hippocampal GABA networks important in anxiety; and identify a potential therapeutic target for anxiety disorders that warrants further investigation in relevant preclinical models.
\end{abstract}

Key Words: adeno-associated virus; GABA; nucleus incertus; parvalbumin; social interaction; somatostatin; ventral hippocampus 


\section{INTRODUCTION}

Anxiety disorders are the most prevalent type of mental disorder, diagnosed in $~ 18 \%$ of the United States adult population (Kessler et al. 2005), and include diverse conditions, such as generalized anxiety, phobic-, panic-, obsessive/compulsive-, and post-traumatic stress disorder (PTSD) (Lenze and Wetherell 2011). Anxiety disorders share both physiological and psychological symptoms, such as dysregulation of brain corticotropin-releasing factor (CRF) systems and plasma cortisol levels (Siegmund et al. 2011), and hypervigilance and social avoidance (LeDoux 2003; Kennedy and Adolphs 2012). Despite their prevalence and socio-economic impact, the neural circuits and synaptic mechanisms underlying anxiety disorders remain quite poorly understood. Current treatment options are limited, and generally comprise agents originally used for treating depression, such as benzodiazepines and selective serotonin reuptake inhibitors (SSRIs), which are associated with major side-effects (Gomez et al. 2018). Thus, new insights into the nature of anxiety-related circuits and their regulation by transmitter and neuromodulatory systems are key to developing better treatments; and research to identify and explore novel structural and molecular therapeutic targets is essential.

The hippocampus has been demonstrated to be important for processing memory and emotions, in both clinical and experimental studies (Scoville and Milner 1957; O'Keefe and Dostrovsky 1971; Squire 1992; Wik et al. 1993; Bremner et al. 1999; MacMillan et al. 2003; Richardson et al. 2004). Lesions of the ventral, but not dorsal, hippocampus and dentate gyrus (DG) in rats, reduced anxietylike behaviour and increased time spent in the aversive open arms of the elevated plus maze (EPM) (Kjelstrup et al. 2002; Weeden et al. 2014), while increased activity in ventral hippocampus (vHip) has been associated with anxious behaviour (Adhikari et al. 2011). These and other studies suggest vHip is crucial for mediating anxious behaviour (Fanselow 2010), and details of the precise networks and neural populations involved are beginning to be identified (Yeung et al. 2011; Felix-Ortiz 2014; Lovett-Barron et al. 2014; Calhoon and Tye 2015; Çalışkan et al. 2016; Padilla-Coreano et al. 2016; 
Stefanelli et al. 2016; Li et al. 2017; Yuan et al. 2017). At a neurochemical level, anxiety is correlated with dysfunctions in hippocampal inhibitory interneuron network activity (Engin and Treit 2007; Kalueff 2007). For instance, selective stimulation of parvalbumin (PV)-expressing GABAergic interneurons in the DG, using designer receptors exclusively activated by designer drugs (DREADDs), reduced anxiety and promoted social interaction behaviour (Zou et al. 2016). Meanwhile, recent studies of somatostatin (SST)-expressing GABAergic neurons in the DG have reported their involvement in memory formation during aversive stimuli (Stefanelli et al. 2016).

The vHip receives/sends information from/to many emotional centres, such as the amygdala (Maren 1995), hypothalamus (Herman et al. 1992; Cenquizca and Swanson 2007) and medial prefrontal cortex (Padilla-Coreano et al. 2016). The vHip also receives a strong noradrenergic input from the locus coeruleus (Pickel et al. 1974), a dopaminergic projection from the ventral tegmental area (Gasbarri et al. 1997), and both serotonergic and non-serotonergic inputs from median and dorsal raphe nuclei (Aznar et al. 2004). It is well established that the inputs from the medial septum (MS) and diagonal band of Broca to the hippocampus are crucial for generating/regulating 'theta rhythm'. The firing of theta-rhythmic septal GABAergic neurons provides a drive for theta oscillations in the hippocampus, as the firing of septal neurons disinhibits principal hippocampal neurons (Hangya et al. 2009).

The vHip also receives a dense input from a population of GABAergic neurons in the hindbrain region known as the nucleus incertus (NI) (Goto et al. 2001; Olucha-Bordonau et al. 2003; Ryan et al. 2011), many of which co-express the neuropeptide, relaxin-3 (Tanaka et al. 2005; Ma et al. 2007)(Ma and Gundlach 2015). In fact, the vHip receives a dense relaxin-3 innervation, and contains a large number of neurons that express the cognate relaxin-3 receptor, known as relaxin-family peptide 3 receptor (RXFP3) (Liu et al. 2003; Sutton et al. 2005; Ma et al. 2007; Ma et al. 2009). Relaxin-3 is an evolutionarily conserved neuropeptide (Wilkinson et al. 2005), and while primarily expressed by NI neurons, it is also present in smaller populations of neurons in the pontine raphe nucleus, an area 
dorsal to the substantia nigra pars compacta and medial and ventrolateral periaqueductal grey (Bathgate et al. 2002; Burazin et al. 2002; Tanaka et al. 2005; Ma et al. 2007; Blasiak et al. 2013). In addition to vHip, relaxin-3-containing nerve fibres strongly innervate other forebrain structures involved in anxiety and fear-related processing, such as the amygdala, bed nucleus of the stria terminalis (BNST), prefrontal cortex, and lateral hypothalamus (Tanaka et al. 2005; Ma et al. 2007).

Recent studies have established a role for relaxin-3/RXFP3 signalling in the regulation of the septohippocampal system, hippocampal theta rhythm, and spatial memory, via actions in the MS and dorsal hippocampus (Ma et al. 2009; Ma et al. 2013; Albert-Gasco et al. 2017; Haidar et al. 2017). Furthermore, chemogenetic activation of NI neurons altered hippocampal activity and theta rhythm, and increased risk assessment behaviour, consistent with an influence of NI GABA and relaxin-3 transmission on affective and cognitive processes (Ma et al. 2017). Notably, all clinically effective anxiolytic drugs reduce the average frequency of brain theta activity, despite their substantial neurochemical dissimilarities (McNaughton and Gray 2000; McNaughton et al. 2007), suggesting that relaxin-3 modulation of hippocampal theta rhythm may also impact anxiety.

Initial pharmacological studies in our laboratory revealed that acute, intracerebroventricular (icv) administration of an RXFP3 agonist, RXFP3-A2, resulted in decreased indices of anxiety-like behaviour in rats in the light-dark box (LDB) and EPM paradigms, but not in the large open-field (LOF) test (Ryan et al. 2013). However, these studies did not identify the brain areas in which these effects were mediated or the identity of the neurons expressing RXFP3 in these areas. In a rodent model of alcohol self-administration and relapse, acute local injection of antagonist has confirmed a role for RXFP3 signalling in specific brain regions on complex behaviours (Ryan et al. 2013). Another approach, which avoids the technical and logistic issues of repeated injections of RXFP3 agonist into brain areas, is a viral-based method for chronic local secretion of an RXFP3-selective agonist (McCown 2006; Ganella et al. 2013). When injected in the PVN, chronic secretion of the RXFP3- 
selective agonist, R3/I5, induced a significant increase in daily food intake and body weight gain, associated with decreases in oxytocin and vasopressin mRNA levels in this region (Ganella et al. 2013).

Therefore, in these studies in adult, male Sprague-Dawley rats, we utilised a highly-sensitive, multiplex fluorescent in situ hybridisation method (RNAscope ${ }^{\mathrm{TM}}$ ) to identify the nature of hippocampal RXFP3-expressing neurons; and examined the effects of chronically enhanced RXFP3 signalling in vHip on indices of anxiety-like and social behaviour. 


\section{MATERIALS AND METHODS}

\section{Animals}

Experiments were conducted with the approval of The Florey Institute of Neuroscience and Mental Health Animal Ethics Committee and according to the guidelines issued by the National Health and Medical Research Council of Australia. All efforts were made to minimise the number of animals used. Male Sprague-Dawley rats supplied by the Animal Resources Centre, Perth, WA, Australia, weighed 250-300 g on arrival. Rats were housed under ambient conditions $\left(21^{\circ} \mathrm{C}\right)$ and maintained on a 12 h light:dark cycle (lights on 0700-1900) with ad libitum access to laboratory chow and water. Rats were acclimatised to the animal facility for at least 1 week prior to experimentation and were individually housed for the entire study.

\section{Multiplex in situ hybridisation histochemistry}

On the basis of the topographic distribution of RXFP3 mRNA in the hippocampus observed in rat (Ma et al. 2007) and mouse brain (Smith et al. 2010); Allen Brain Atlas; www.brain-map.org), multiplex in situ hybridisation (ISH) was performed to determine the neurochemical phenotype of RXFP3 mRNApositive vHip neurons. Naïve rats were deeply anesthetised with sodium pentobarbital $(100 \mathrm{mg} / \mathrm{kg}$, i.p., Virbac, Milperra, NSW, Australia), decapitated, and brains were rapidly collected, frozen over dry ice and stored at $-80^{\circ} \mathrm{C}$. Fresh frozen coronal sections $(16 \mu \mathrm{m})$ through the vHip were cut at $-16^{\circ} \mathrm{C}$ (Cryocut 1800, Leica Microsystems, Heerbrugg, Switzerland) and thaw-mounted onto Superfrost Plus slides (Thermo Fisher Scientific, Melbourne, Australia). Slides were processed according to the manufacturer's protocol (Advanced Cell Diagnostics (ACD), Hayward, CA, USA) using specific ACD probes for mRNA encoding Rxfp3 (probe \#316181), vesicular $\gamma$-aminobutyric acid transporter (vGAT, Slc32a1, probe \#316181) somatostatin (SST, probe \#412181), and parvalbumin (PV, probe \#407821). 
Following ISH, sections were stained with DAPI (ACD), coverslipped with Fluoromount-G (Southern Biotech, Birmingham, AL, USA) and imaged.

\section{Stereotaxic surgery and viral vector infusions}

Rats were initially anaesthetised by inhalation of $4 \%$ isoflurane in an enclosed vessel and maintained with $2 \%$ in $200 \mathrm{ml} / \mathrm{min}$ air via an anaesthetic mask (Kopf Instruments, Tujunga, CA, USA) fitted on a stereotaxic frame (Kopf Instruments). The head was shaved and swabbed with 10\% povidone-iodine (Riodine; ORION Laboratories Pty Ltd., Balcatta, WA, Australia) and treated with ilium lignocaine (5 mg/kg, s.c.; Troy Laboratories, Australia). Rats were also treated with pre-operative meloxicam (3 $\mathrm{mg} / \mathrm{kg}$, i.p.). Two burr holes in the skull were drilled targeting the vHip at stereotaxic coordinates relative to bregma: AP $-5 \mathrm{~mm}, \mathrm{ML} \pm 5 \mathrm{~mm}$, DV $-7 \mathrm{~mm}$ (Paxinos and Watson 2006). Rats were randomly assigned to control or agonist groups, and received bilateral $1 \mu \mathrm{l}$ infusions $(0.5 \mu \mathrm{l} / \mathrm{min})$ of either $\mathrm{AAV}^{1 / 2}$-sCAG-eGFP control vector $\left(7.73 \times 10^{10} \mathrm{gc} / \mathrm{ml}\right)$ or $\mathrm{AAV}^{1 / 2}$-FIB-R3/I5 agonist vector $\left(4.75 \times 10^{12} \mathrm{gc} / \mathrm{ml}\right)$. The latter vector, which contains a fibronectin secretory sequence (FIB), to ensure constitutive secretion from transduced neurons at the site of injection (McCown 2006; Ganella et al. 2013), was diluted with the GFP-expressing control vector in a 9:1 ratio (with GFP-expressing control vector being $10 \%$ of the injected mixture) to assist with targeting (see Fig. 1). Viral vectors were delivered by a pulled glass micropipette connected to a $1 \mu$ l Hamilton syringe (Harvard Apparatus, Holliston, MA, USA). The AAV ${ }^{1 / 2}$-FIB-R3/I5 agonist vector has been validated in vitro and in vivo (Ganella et al. 2013). Subsequent cohorts used a newly devised and validated agonist vector $\mathrm{AAV}^{1 / 2}$ sCAG-R3/I5-IRES-eGFP $\left(2 \times 10^{11} \mathrm{gc} / \mathrm{ml}\right)$, which is structurally identical to the previous vector with the advantage of an incorporated GFP fluorophore (see Fig. 1). The injector was kept in place for 10 min, retracted $1 \mathrm{~mm}$, kept in place for a further $1 \mathrm{~min}$ before complete withdrawal, to maximize diffusion. The incision was sutured, swabbed with povidone-iodine, and rats regained consciousness in 
a warm chamber. Rats were left for 3 weeks prior to behavioural testing to allow maximal viral transduction.

\section{Behavioural testing}

Behavioural tests were conducted during the light phase (between 7:00-19:00) and rats were habituated to the behavioural test room prior to experimentation. A minimum of one day between experiments was allowed for sufficient rest and recovery. Each trial lasted $10 \mathrm{~min}$ and the apparatus was wiped with $80 \%$ ethanol and dried between rats.

\section{Elevated plus maze}

The EPM consisted of four arms, $30.5 \mathrm{~cm}$ (length) $\times 5 \mathrm{~cm}$ (width) $\times 38.7 \mathrm{~cm}$ (height) projecting from a central square $(5 \mathrm{~cm} \times 5 \mathrm{~cm})$. Two opposing arms were enclosed by $15.2 \mathrm{~cm}$ walls (designated 'closed' arms), while the 'open' arms had a $0.9 \mathrm{~cm}$ ledge to prevent rats from slipping off. The apparatus was placed in the middle of the experimental room under low light ( $\sim 50$ lux closed arms, 70 lux open arms) and behaviour was recorded and analysed by TopScan software (CleverSys, Reston, VA, USA) via an overhead camera. Arm entries, time spent in arms, distance travelled in arms and latency to enter open arms (all four feet in outer half of the open arm) were quantified.

\section{Light-dark box}

Rats were placed into an automated clear-walled locomotor arena measuring $43.2 \mathrm{~cm} \times 43.2 \mathrm{~cm} \times 30.5$ cm, encased by two photobeam rings (Rat Open Field Arena, ENV-515; MED Associates Inc., St. Albans, VT, USA). A black, opaque plastic insert measuring $21.6 \mathrm{~cm} \times 21.6 \mathrm{~cm} \times 30 \mathrm{~cm}$ was used to create the dark zone ( $\sim 2$ lux interior). The light zone was lit with an array of light-emitting diodes ( 600 lux in the centre). A small entry door enabled rats to move between the dark and light zones. The TruScan 2.04 software (Coulburn Instruments, Whitehall, PA, USA) was used to analyse 
horizontal and vertical movements in the arena recorded by photobeams. Zone entries, time spent in each zone, and distance travelled in each zone, as well as latency to enter the light zone were analysed.

\section{Large open-field}

The LOF was a $1.4 \mathrm{~m}$ diameter circular arena on the floor of an experimental room, surrounded by a $60 \mathrm{~cm}$ high aluminium wall. The arena was divided into two regions: a 'centre' region of $0.45 \mathrm{~m}$ in diameter, and an outer 'periphery' region of $0.15 \mathrm{~m}$. The arena was lit using a flood light mounted on the ceiling ( 1200 lux in the centre and 1000 lux at the periphery). Rats were placed in the centre of the arena prior to a $10 \mathrm{~min}$ trial and time spent, distance travelled in each region, as well as latency to enter the centre region was analysed using TopScan software (CleverSys, Reston, VA, USA).

\section{Social interaction test}

Each rat was placed in the centre of a $1 \mathrm{~m} \times 1 \mathrm{~m}$ square arena with a $30 \mathrm{~cm}$ wall, and allowed to habituate for $1 \mathrm{~min}$. A conspecific 'stranger' rat of matched age and gender was placed in the centre of the arena and their interactions were recorded during a 10 min trial. SocialScan software (CleverSys, Reston, VA, USA) was used to analyse social behaviours, including time spent in active and passive contact, contact to specific body parts, approach, leave, follow, sniffing, mounting, and distance from stranger.

\section{Validation of GFP targeting in vHip}

At the end of behavioural testing, rats were deeply anesthetised with sodium pentobarbital $(100 \mathrm{mg} / \mathrm{kg}$, i.p.) prior to transcardial perfusion with $300 \mathrm{ml}$ ice-cold $0.1 \mathrm{M}$ phosphate-buffered saline (PBS: 137 $\mathrm{mM} \mathrm{NaCl}, 2.7 \mathrm{mM} \mathrm{KCl}, 11.2 \mathrm{mM} \mathrm{Na}_{2} \mathrm{HPO}_{4}, 1.8 \mathrm{mM} \mathrm{KH}_{2} \mathrm{PO}_{4}$, pH 7.4) followed by $400 \mathrm{ml} 4 \%$ paraformaldehyde in $0.1 \mathrm{M}$ PBS. Brains were isolated and postfixed in fixative for $1 \mathrm{~h}$ then transferred to $30 \%$ sucrose-PBS solution at $4^{\circ} \mathrm{C}$ for at least $48 \mathrm{~h}$.

Coronal sections $(40 \mu \mathrm{m})$ containing vHip were imaged for native eGFP fluorescence on an Olympus 
BX51 upright immunofluorescence microscope (Olympus Imaging, Notting Hill, Australia). Images of viral injection sites were imaged with a $5 \times$ objective and intensity thresholds adjusted to accurately quantify moderate- to high-expressing eGFP fluorescent cells. For histological assessment, corresponding sections from each rat along the AP axis of the vHip were imaged and cell body fluorescence spread was mapped onto representative rat brain atlas plates (Fig. 2) (Paxinos and Watson 2006).

\section{Immunohistochemistry}

Free-floating coronal sections $(40 \mu \mathrm{m})$ were cut on a cryostat at $-18^{\circ} \mathrm{C}$ (Cryocut 1800 , Leica Microsystems) and collected into 0.1 M PBS. Sections were washed $3 \times 10 \mathrm{~min}$ in PBS and blocked with $10 \%$ normal horse serum (NHS), $0.1 \%$ Triton X-100 in PBS for $1 \mathrm{~h}$ at room temperature. Sections were then incubated in 2\% NHS, $0.1 \%$ Triton X-100 in PBS containing mouse monoclonal relaxin-3 antibody (HK4-144-10; 1:5; (Kizawa et al. 2003; Tanaka et al. 2005; Ma et al. 2007), rat polyclonal somatostatin antibody (Millipore, MAB354, 1:200), polyclonal rabbit parvalbumin antibody (Abcam, ab11427, 1:500), or polyclonal rabbit cleaved caspase-3 antibody (Cell Signaling Technology, \#9661, 1:5000) overnight at $4^{\circ} \mathrm{C}$. Control sections were incubated without primary antibody. On the following day, sections were washed $3 \times 10 \mathrm{~min}$ in PBS prior to $1 \mathrm{~h}$ incubation in donkey anti-mouse AlexaFluor-488 (Life Tech, A21206, 1:500), and donkey anti-rat AlexaFluor-594 (Jackson Immunoresearch, 712-586-150, 1:500), or anti-rabbit AlexaFluor-647 (Jackson Immunoresearch, 711-605-152), and donkey anti-mouse Alexa-594 (Jackson Immunoresearch, 715585-151, 1:500) in $0.1 \mathrm{M}$ PBS for $1 \mathrm{~h}$ at room temperature. The reaction was stopped by $3 \times 5 \mathrm{~min}$ PBS washes and the sections were mounted onto glass microscopy slides before being coverslipped with Fluoromount-G (Southern Biotech, Birmingham, AL, USA).

\section{Fluorescence microscopy and imaging analysis}

Imaging of ISH and immunofluorescence was performed using LSM 780 Zeiss Axio Imager 2 
confocal laser scanning microscope (Carl Zeiss AG, Jena, Germany). The system is equipped with a stitching stage and Zen software (Carl Zeiss AG) was used to stitch tiled images. To assess mRNA colocalisation in vHip, each fluorescence channel and probe was imaged sequentially using a $20 \times$ objective and the entire vHip reconstructed from stitched images. DAPI-stained nuclei with $>5$ fluorescence particles were considered as mRNA-expressing. The percentage co-localization of RXFP3, SST, and PV mRNA was assessed at matching rostro-caudal levels of the CA1 and CA3 subfields of vHip. Data were collected from 2-3 naïve rats. Three analogous sections that contain the vHip were delineated into CA1 and CA3 regions (as defined in the Rat Brain Atlas, (Paxinos and Watson, 2006)). Each region was imaged and neurons were counted using FIJI software for mRNA expression in each layer within each region. For immunofluorescence, each fluorescence channel was imaged sequentially using a $20 \times$ or $63 \times$ objective. High magnification images were collected at $63 \times$ through the entire Z-plane and collapsed into maximum projection images. Data is presented as mean \pm SEM.

\section{Statistical analysis}

Data analysis and graph generation was performed using GraphPad Prism 7.0 (GraphPad Software, San Diego, CA, USA) and results are expressed as mean \pm SEM. For behavioural data, statistical significance between control and agonist-treated groups was evaluated using unpaired Student's t-test. 


\section{RESULTS}

\section{Identification of RXFP3 mRNA-expressing neurons in hippocampus of naïve rats}

On the basis of the topographic distribution of RXFP3 mRNA in the hippocampus in rat (Ma et al. 2007) and mouse brain (Smith et al. 2010; Allen Brain Atlas; www.brain-map.org), multiplex ISH was performed using naïve rat brains. The aim of these studies was to determine the regional distribution of RXFP3 mRNA-positive neurons across the hippocampus and to identify if labelled neurons were GABAergic in nature, reflected by expression of the vesicular GABA transporter (vGAT) mRNA (Chaudhry et al. 1998). In addition, RXFP3 mRNA-positive neurons were examined for co-expression of SST and PV mRNA, to reflect two key peptide/protein markers of hippocampal GABA neurons (Klausberger and Somogyi 2008). The topographic expression pattern of SST and PV mRNA in the polymorphic layer of the DG and stratum oriens layer of the CA1 and CA3 hippocampal subfields correlates well with that of RXFP3 mRNA (Katsumaru et al. 1988; Esclapez and Houser 1995; Ma et al. 2007).

As predicted, multiplex ISH revealed that RXFP3 mRNA was expressed in vGAT mRNA-positive neurons in the CA1, CA3, and DG subfields of vHip (Fig. 3A, B) and in SST mRNA- and PV mRNApositive neurons (Fig. 3C-E). In line with the abundance of SST and PV neurons in these regions, RXFP3 mRNA expression was abundant in the oriens and hilar layers. In the material examined, in the CA1 subfield, RXFP3 mRNA was expressed in 34\% of SST mRNA-positive neurons (22 \pm 2 of $64 \pm$ $1, \mathrm{n}=3$ ), and in $\sim 13 \%$ of PV mRNA-positive neurons ( $8 \pm 2$ of $63 \pm 14$; $n=2$; Fig. 4). In the CA3, $\sim 26 \%$ of SST mRNA-expressing neurons (19 \pm 2 of $74 \pm 4, n=3$; Fig 3C), and $\sim 25 \%$ of PV mRNAexpressing neurons (16 \pm 0 of $65 \pm 7, n=2$; Fig. 3E) co-expressed RXFP3 mRNA (Fig. 4). In the total population of RXFP3 mRNA-expressing neurons detected in the CA1 subfield, 36\% (16 \pm 2 of $45 \pm$ $1, \mathrm{n}=2)$ were SST mRNA-positive only, $22 \%(10 \pm 1$ of $45 \pm 1, \mathrm{n}=2)$ were PV-mRNA positive 
only, and $~ 13 \%$ (6 \pm 1 of $45 \pm 1, \mathrm{n}=2$ ) co-expressed both SST and PV mRNA (Fig. 4). In the CA3, $\sim 37 \%$ of all RXFP3 mRNA-expressing neurons co-expressed SST mRNA (19 \pm 2 of $51 \pm 4, n=2)$, and $\sim 31 \%$ co-expressed PV mRNA (16 \pm 0 of $51 \pm 4, \mathrm{n}=2$ ), and $\sim 9 \%(4 \pm 1$ of $45 \pm 1, \mathrm{n}=2$ ) coexpressed both SST and PV mRNA (Fig. 4). In this study, we did not quantify the level of coexpression of RXFP3 mRNA with SST or PV mRNA in the hilus, as this region will be the subject of separate further investigation.

No RXFP3 mRNA was detected in non-vGAT mRNA-positive neurons in CA1/CA3 principal layers or the DG granule cell layer. However, we cannot exclude the possible expression of RXFP3 mRNA in other major or minor populations of hippocampal GABAergic projection- or inter-neurons (i.e. nonSST, non-PV mRNA-positive neurons; see Fig. 3C-E), and further studies would be required to explore further possibilities.

In the current study, we did not conduct a quantitative analysis of the relative number and neurochemical phenotype of RXFP3 mRNA-positive neurons in dorsal and vHip, but a qualitative examination of sections through the dorsal region from up to three rats, indicated that the density RXFP3 mRNA-positive neurons was lower in the dorsal region than in the VHip, in line with previous reports in the rat (Ma et al. 2007), and the apparent differential receptor density in the mouse hippocampus (Smith et al. 2010, Allen Brain Atlas; <www.brain-map.org>). Furthermore, RXFP3 mRNA was similarly co-expressed with SST and PV mRNA in equivalent layers of the dorsal and vHip.

\section{Relaxin-3 innervation of vHip neurons}

In naïve rats, dense relaxin-3-immunoreactive fibres were observed in vHip, with a particularly dense plexus in the polymorphic layer of the DG, CA1 oriens layer, and across the CA3 region (Ma et al. 2007). In the current studies, relaxin-3-immunoreactive fibres were detected in close vicinity to SST- 
and PV-immunoreactive neurons in the CA1 oriens layer, as well as in CA3 oriens and DG polymorphic layers (Fig. 5), further suggesting that hippocampal GABA neuron activity is regulated by relaxin-3/RXFP3 signalling (see also Haidar et al. 2017). Future studies employing presynaptic and postsynaptic protein markers, and higher-resolution fluorescence or electron microscopy could also better identify the precise nature of the putative synaptic contacts between relaxin-3-containing fibres and SST- and/or PV- GABAergic neurons.

\section{Transduction of vHip neurons with $\mathrm{AAV}^{1 / 2}$-sCAG-GFP and AAV ${ }^{1 / 2}$-R3I5-IRES-eGFP}

Strong, persistent eGFP expression induced by $\mathrm{AAV}^{1 / 2}$-sCAG-GFP (hereafter referred to as vHipeGFP) and $\mathrm{AAV}^{1 / 2}$-FIB-R3/I5-IRES-eGFP (hereafter referred to as vHip-R3/I5) viral vectors was observed in vHip neurons up to 3 months post-injection. A series of four analogous coronal sections from the vHip of each rat was used to create comparative eGFP expression profiles (Fig. 2). Rats from two different cohorts were included in the analysis, and only rats that displayed somatic eGFP immunofluorescence in one or more vHip regions - CA1, CA3, or DG, were included in the data analysis. Three rats were observed to have a unilateral distribution of eGFP, and presumed chronic R3/I5 synthesis and secretion unilaterally in vHip. Nonetheless, analysis revealed that their behaviour was comparable to, and not significantly different from, that of bilaterally targeted rats, and therefore these rats were included in the vHip-R3/I5 group.

\section{Chronic RXFP3 activation in vHip induces anxiety-like behaviour}

In the EPM, rats in the vHip-R3/I5 group spent significantly less time in the open arms compared to control vHip-eGFP rats $\left(\mathrm{t}_{(16)}=2.9, \mathrm{p}=0.01, \mathrm{n}=7-11\right.$ rats per group), which was associated with decreased distance travelled in the open arms compared to control $\left(t_{(16)}=3.05, p=0.008\right.$; Fig. 6A). In addition, the vHip-R3/I5 group performed significantly less entries into the open arms $\left(\mathrm{t}_{(16)}=2.9, \mathrm{p}=\right.$ 0.01). Conversely, the vHip-R3/I5 rats spent significantly more time in the closed arms compared to control $\left(\mathrm{t}_{(16)}=3.8, \mathrm{p}=0.002\right)$, and travelled less distance in the closed arms $\left(\mathrm{t}_{(16)}=2.5, \mathrm{p}=0.02\right)$. 
However, no differences were observed in the number of entries into the closed arms $\left(\mathrm{t}_{(16)}=1.86, \mathrm{p}=\right.$ 0.08). Furthermore, the total distance travelled by vHip-R3/I5 rats was significantly less than the control group $\left(\mathrm{t}_{(16)}=3.33, \mathrm{p}=0.004\right)$, suggesting an impact on locomotor activity in this test.

In the LDB, rats in the vHip-R3/I5 group spent significantly less time $\left(\mathrm{t}_{(16)}=4.59, \mathrm{p}=0.0003\right)$, and travelled less distance $\left(\mathrm{t}_{(16)}=3.40, \mathrm{p}=0.004\right)$ in the light compartment compared to control vHipeGFP rats (Fig. 6B). However, the two groups did not differ in distance travelled in the dark compartment $\left(\mathrm{t}_{(16)}=2.05, \mathrm{p}=0.06\right)$, or the number of compartment crossings $\left(\mathrm{t}_{(16)}=1.23, \mathrm{p}=0.24\right)$, indicating that chronic vHip RXFP3 stimulation did not affect locomotor ability and drive to explore the light compartment, respectively, but was specific in promoting avoidance of the light compartment. In contrast with EPM, there was no difference in total distance travelled in the LDB between the vHip-R3/I5 and control groups $\left(\mathrm{t}_{(16)}=1.28, \mathrm{p}=0.21\right)$.

In the LOF, no significant differences were observed between vHip-R3/I5 and vHip-eGFP groups in the average number of entries $\left(\mathrm{t}_{(16)}=1.91 ; \mathrm{p}=0.07\right)$; time spent in the centre $\left(\mathrm{t}_{(16)}=0.57, \mathrm{p}=0.58\right)$, distance travelled in the centre $\left(\left(\mathrm{t}_{(16)}=1.14 ; \mathrm{p}=0.27\right)\right.$, or in total distance travelled $\left(\mathrm{t}_{(16)}=1.65 ; \mathrm{p}=\right.$ 0.12; Fig. 7), suggesting no impact on anxiety or locomotor activity in this test.

\section{Chronic activation of RXFP3 in vHip leads to a decrease in social interaction}

In a social interaction test, vHip-R3/I5 rats exhibited significantly less social approach $\left(\mathrm{t}_{(16)}=2.94, \mathrm{p}=\right.$ 0.009), follow $\left(\mathrm{t}_{(16)}=2.88, \mathrm{p}=0.01\right)$, and sniff $\left(\mathrm{t}_{(16)}=2.6, \mathrm{p}=0.04\right)$ behaviours, which in turn, was associated with increased passive social contact (i.e. less contact initiation; $t_{(16)}=3.72, p=0.009$ ), in response to a stranger conspecific rat, compared to control vHip-eGFP rats (Fig. 8). vHip-R3/I5 rats did not exhibit a difference in social leave behaviour $\left(\mathrm{t}_{(16)}=1.3, \mathrm{p}=0.21\right)$ or social mounting $\left(\mathrm{t}_{(16)}=\right.$ 2.02, $\mathrm{p}=0.06)$. 


\section{DISCUSSION}

These studies have revealed a novel action of the relaxin-3/RXFP3 signalling system in the vHip through identification of the RXFP3-expressing target neurons and characterisation of robust anxiogenic effects following chronic RXFP3 activation. In light of the identified inhibitory effect of acute RXFP3 activation on neurons in rat thalamus and hypothalamus (Blasiak et al. 2013; Kania et al. 2017), the likely chronic inhibition of multiple hippocampal GABAergic neuron populations suggests several putative mechanisms for altering hippocampal output and inducing anxiety-like behaviour that warrant investigation in future studies. These possible actions and the implications of the current findings are discussed below.

In the EPM, rats face conflict between exploration of a novel environment and innate aversion of elevated and open spaces. In the current study, the vHip-R3/I5 group exhibited significantly less time and distance travelled in, and fewer entries into the open arms of the maze, as well as less total distance travelled than control rats, which is reflective of increased anxiety and/or a potential sedative effect of the agonist. The latter effect is not consistent, however, with previous experiments demonstrating that viral vector-mediated chronic secretion of RXFP3 agonist within the cerebroventricular system reduced locomotor habituation to a novel environment in mice (Smith et al. 2013). This difference may be species-related, or is more likely due to site-specific differential actions of RXFP3 activation, which is further discussed below.

Moreover, there were no difference between groups in the number of entries into closed arms, indicating that vHip-R3/I5 rats specifically avoided the open elevated platforms, naturally aversive to rats (Walf 2007). Similarly, the LDB test is based on conflict between exploration of a novel environment and an aversion of brightly illuminated spaces with preference for dark, 'safe' environments (Merlo Pich 1989). In this test, the vHip-R3/I5 rats spent significantly less time and travelled less distance in the light compartment than control rats, which is reflective of increased 
avoidance and anxiety-like behaviour. There were no difference between groups in the number of compartment crossings and distance travelled in the dark compartment, indicating that chronic RXFP3 activation did not affect the drive to initially investigate the light compartment or general locomotor activity. There was also no significant difference in the total distance travelled by each group in the LDB, implying normal overall activity. Finally, the LOF is a test in which rats exhibit conflict between exploration of a novel environment and aversion of a brightly illuminated centre space, with an innate preference to remain close to the wall (thigmotaxis). In this test, however, vHip-R3/I5 rats did not display any significant differences in behaviour compared to control rats, which may be due to the lack of an escape from the 'stressor' (brightly-lit circular arena), in contrast to the LDB and EPM paradigms which provide 'safe zones' in the dark compartment and closed arms, respectively. Similar to performance in the LDB, there was no difference in the total distance travelled by vHip-R3/I5 and vHip-eGFP control rats in the LOF, indicating that chronic RXFP3 activation in vHip had no major effects on locomotor activity in this paradigm.

Notably, this is the first study of relaxin-3/RXFP3 signalling in social behaviour, whereby vHip-R3/I5 rats exhibited significantly reduced measures of various social interactions with a conspecific rat, compared to control rats. Specifically, they spent less time in social approach, follow, and sniff, and increased passive social contact (i.e. less initiation of contact). Although earlier studies have reported that the vHip does not play a crucial role in social interaction in adulthood (Sams-Dodd et al. 1997; Becker et al. 1999), lesion studies have illustrated its likely role in regulating social behaviour (Cadogan et al. 1994; Pentkowski et al. 2006). More recent studies have revealed that the vHipbasolateral amygdala (BLA) circuit bi-directionally modulates non-competitive social behaviour (Felix-Ortiz and Tye 2014), and that CA1 pyramidal neurons in the vHip are 'necessary and sufficient' for social memory formation and recall (Okuyama et al. 2016). Importantly, impairments in social interaction are a common feature in psychiatric disorders, including ADs (Kennedy and Adolphs 
2012); and the involvement of relaxin-3/RXFP3 circuitry in regulating anxiety is consistent with an impact on social behaviour. Together, our findings point to a role for relaxin-3/RXFP3 signalling in the vHip in social behaviour and expression of anxiety-like behaviours.

The anxiogenic phenotype associated with chronic RXFP3 agonist secretion in the vHip contrasts with the anxiolytic phenotype of rats receiving acute, intracerebroventricular infusions of an RXFP3 agonist (Ryan et al. 2013). These data suggest that pharmacological RXFP3 activation can differentially affect anxiety-like behavioural responses depending on the precise site(s) of action (and possibly duration of action). While broad activation of RXFP3 in brain regions proximal to the lateral cerebral ventricle may be anxiolytic, restricted activation of RXFP3 in the vHip is anxiogenic. In this regard, it is not unprecedented for neuropeptide receptor activation to affect behaviour in this bidirectional fashion. For example, icv administration of CRF was shown to increase anxiety (Adamec and McKay 1993) and reduce social interaction behaviour (Dunn and File 1987), whereas local CRF infusion into the globus pallidus has been associated with anxiolytic effects (Sztainberg et al. 2011). Conversely, local CRF infusion into vHip increased anxiety and defensive behaviours via activation of $\mathrm{CRF}_{1}$ receptors (Radulovic et al. 1999; Pentkowski et al. 2009). The differential effects of RXFP3 agonist administered via different routes may also be partly attributed to the temporal differences in action after acute icv injections versus chronic, local synthesis of RXFP3 agonist. Therefore, further studies comparing acute agonist injections into the vHip with chronic activation of RXFP3 via the icv route are warranted. Another possibility is that chronic RXFP3 activation in regions that are more readily targeted by icv RXFP3 agonist than the vHip might recapitulate the anxiolytic effects seen after icv administration.

Furthermore, in the future it would be of interest to assess the comparative behavioural and neurochemical effects of chronic RXFP3 activation in the dorsal hippocampus, as this region also receives a topographic relaxin-3 innervation and expresses RXFP3 (Tanaka et al. 2005; Ma et al. 
2007; Ma and Gundlach 2015), and different amino acid, monoamine and peptide transmitters have been implicated in the control of anxiety via actions in this area in several earlier and recent investigations (see e.g. File et al. 2000; Solati et al. 2010; McEown and Treit 2013; Funck et al. 2018; Gunther et al. 2018).

Nonetheless, the current data reflects the effects of long-term, elevated and exogenously-driven RXFP3 signalling in the vHip to produce an anxiogenic and asocial phenotype. This allows some speculation about the nature of endogenous relaxin-3/RXFP3 signalling in vHip under different conditions. As mentioned, there is a very dense innervation of the vHip by the NI, particularly of the hilus region (Goto et al. 2001; Olucha-Bordonau et al. 2003), and studies in our laboratory have identified an equivalent high density of relaxin-3 positive fibres in this region, relative to a lower density in the dorsal Hip (Ma et al. 2007). It is well established that relaxin-3 neurons are stressreactive in rats (Tanaka et al. 2005; (Banerjee et al. 2010; Tanaka 2010; Ma et al. 2013), and there is clear evidence that the relaxin-3/RXFP3 system interacts with the CRF/CRF 1 system within the brainstem and forebrain (Huang et al. 2006; Farooq et al. 2013; Farooq et al. 2013; Lenglos et al. 2013; Ma et al. 2013; Ma and Gundlach 2015; Walker et al. 2015; Walker et al. 2017). Therefore, it will be of interest to further probe the nature of endogenous relaxin-3/RXFP3 signalling in the vHip and its effects on behaviour under different stress conditions. Relaxin-3 gene expression and peptide levels have been shown to be altered by acute and chronic stressors that involve the CRF/CRF 1 system, HPA axis, and circulating stress hormones (Ribeiro-Barbosa et al. 2005; Huang et al. 2006; Banerjee et al. 2010; Ma et al. 2013). However, despite a recent investigation in a feeding and obesity model (Lenglos et al. 2014), none of the previous studies have focused on expression changes in the hippocampus and monitored levels of relaxin-3 immunostaining or RXFP3 expression under these conditions. This should be a fruitful area of investigation, particularly as the current study identified 
important populations of RXFP3-targeted neurons in this region, namely SST and PV GABAergic neurons.

Indeed, SST and PV are co-expressed with GABA in hippocampal neurons (Esclapez and Houser 1995; Katsumaru et al. 1988) and SST receptors are abundant in limbic regions devoted to anxiety processing, including amygdala, hippocampus and septum (Schindler et al. 1997; Stroh et al. 1999). Thus, based on the similar topography of RXFP3 mRNA-positive neurons and SST and PV GABAergic interneurons in the ventral hippocampus (Esclapez and Houser 1995; Katsumaru et al. 1988; Ma et al. 2007), we hypothesized that RXFP3-expressing neurons in vHip are GABAergic, and confirmed this by detecting co-expression of RXFP3 and vGAT mRNA. We also demonstrated that RXFP3 mRNA is co-expressed in a significant proportion of SST mRNA- and a smaller proportion of PV mRNA-expressing neurons in the vHip. And using immunohistochemistry, relaxin-3-positive nerve fibres/terminals were detected in close vicinity of SST- and PV-immunoreactive neurons throughout key layers of the vHip (see also Haidar et al. 2017). In line with the likely regulation of SST- and PV-immunoreactive GABA neurons in the vHip by relaxin-3/RXFP3 signalling, in a recent preliminary investigation we observed decreased cellular SST-immunoreactivity in the CA1 and DG subfields and decreased PV-immunoreactivity in the DG subfield of vHip-R3/I5 rats, compared to levels in control rats (data not shown). These data warrant further quantitative studies of the impact of acute and chronic pharmacological RXFP3 activation on the activity and gene and peptide/protein expression profiles of the SST- and PV- GABA neurons in all hippocampal zones in response to different stressors and behavioural challenges, with further elucidation of their neurochemistry, morphology and connectivity within the hippocampal principal and granule cell layers.

Our functional findings are consistent with recent evidence of a differential contribution of distinct hippocampal subfields to anxiety-like behaviour. For instance, optogenetic activation of granule cells in the ventral, but not dorsal DG, reduced innate anxiety behaviour in mice (Kheirbeck et al. 2013). 
More recent studies using both calcium imaging and optogenetics demonstrated that attenuating the activity of neurons in the ventral CA1 decreased anxiety-like behaviour of mice in the EPM, while activation of ventral CA1 neurons projecting to the lateral hypothalamus increased anxiety-like behaviour in the open field test (Jimenez et al. 2018). In our current model of RXFP3 action, a presumed inhibition of SST- and PV- interneurons, in the ventral DG and CA1 in particular, increases anxiety-like behaviour, consistent with these studies.

Our findings also contribute to a number of functional studies that demonstrate the involvement of hippocampal GABA in anxiety (Kalueff and Nutt 1996; Engin and Treit 2007; Kalueff 2007; Guilloux et al. 2012; Nuss 2015), and studies alluding to the role of SST in ADs (Lin and Sibille 2013, 2015). In line with this, acute injections of bicuculline, a $\mathrm{GABA}_{\mathrm{A}}$ receptor antagonist, directly into the vHip increased anxiety-like behaviour in rats, and reversed anxiolytic effects of $\mathrm{GABA}_{\mathrm{A}}$ receptor agonists (Rezvanfard et al. 2009). Furthermore, genetic deletion of the $\gamma$-GABA $A_{A}$ receptor subunit (essential for GABAergic synaptic inhibition) from SST-positive neurons was anxiolytic, via a process of disinhibition of SST neurons, resulting in enhanced inhibition of pyramidal CA1 neurons (Fuchs et al. 2017). These findings support the idea that sustained inhibition of vHip SST/GABA neurons, presumably via chronic RXFP3 signalling, would promote anxiety-like behaviour. Moreover, a recent study revealed that Sst gene knock-out (KO) mice exhibited increased anxiety-like behaviour in the EPM paradigm (Lin and Sibille 2015). Previous research has shown that acute icv (Engin et al. 2008) and intra-amygdala and intra-MS infusions of SST were anxiolytic in rats (Yeung et al. 2011), and could be reversed by administration of an SST receptor-specific antagonist (Yeung and Treit 2012). Supporting these findings, injection of SST into the MS decreased hippocampal theta rhythm (Bassant et al. 2005), a prominent feature of anxiolytic drugs (McNaughton et al. 2007).

Similarly, hippocampal PV GABAergic interneurons have been implicated in anxiety and social behaviours (Sun et al. 2016; Wöhr et al. 2015; Çalışkan et al. 2016). Activation of these neurons in the 
vHip of mice induced anxiolytic effects in the EPM and impaired social behaviour (Zou et al. 2016), while PV KO mice have been shown to display significant deficits in social interaction and serve as a model for autism spectrum disorders (Wöhr et al. 2015). Moreover, a rat model of PTSD displayed anxiety-like behaviour in the EPM and LOF, accompanied by significant decreases in glutamic acid decarboxylase (GAD)-67, a marker of GABAergic neurons, and PV immunoreactivity (Sun et al. 2016). In the current study, we have shown that a population of vHip RXFP3 mRNA-expressing neurons co-express PV mRNA. Thus, the anxiogenic and asocial phenotypes observed following chronic RXFP3 activation in vHip may be mediated by SST- and PV-expressing interneurons and their interactions with each other and their principal neuron targets. Indeed, there are multiple locations and circuits that may underlie these behavioural phenotypes. In the hippocampus, GABA neurons expressing SST are widely but topographically distributed, with a dense population in the polymorphic layer (hilus) of the DG and in the stratum oriens layer of CA1 and CA3 (Buckmaster et al. 1994; Esclapez and Houser 1995).

It is also clear that pharmacological modulation of distinct SST and PV neuron populations will have discrete and ultimately integrated effects on local network function and hippocampal outputs. Therefore, in the future, it will be of interest to determine which SST/GABA and PV/GABA neuron populations are altered by endogenous RXFP3 signalling and how this underlies different behavioural states. It will also be important to further assess the effect of RXFP3 activation on the neurophysiological activity of the hippocampus under conditions such as the home cage and in tests of anxiety or social interaction, including recordings of local field potentials and hippocampal theta, since suppression of hippocampal theta is a well-established feature of anxiolytic agents, while its elevation is associated with anxiety; and recent evidence confirms a strong association between a major group of relaxin-3 neurons in the NI and likely relaxin-3/RXFP3-mediated modulation of 
hippocampal theta (Ma et al. 2009; Ma and Gundlach 2015; Ma et al. 2017; Martínez-Bellver et al. 2017).

While our viral-based approach of chronic vHip RXFP3 activation disrupted the inhibitory neural network by sustained occupation and activation of RXFP3 located on distinct populations of SST/GABA, PV/GABA, and SST/PV/GABA neurons in the vHip, to produce anxiety-like and asocial behaviour, the pattern and level of receptor activation is likely to be distinct from that under normal physiological conditions, where these neurons are inhibited intermittently. It is likely that any naturally occurring differential levels of endogenous RXFP3 signalling within the hippocampus do not mimic the distinct behavioural phenotypes observed in these studies, although this possibility could perhaps be explored experimentally in the future, with appropriate technology. Nonetheless, our paradigm may be mimicking chronic ADs, which are associated with chronic dysregulation of GABAergic signalling (Nuss 2015), particularly in light of evidence of the dysfunction of hippocampal SST (Lin and Sibille 2013, 2015; Schmid et al. 2016) and PV interneurons (Marin 2015; Winkelmann et al. 2014) in neurological and psychiatric disorders.

Together, our results further elucidate the role of relaxin-3/RXFP3 signalling in anxiety-related behaviour in hippocampal-specific circuits, and support a possible role for GABA dysfunction in vHip in specific anxiogenic and asocial behaviours observed across ADs. In addition, the current findings contribute to the literature regarding the functional implications of SST and PV interneuron activity in emotional behaviour and cognition, and are the first to document the interaction between relaxin3/RXFP3, and SST- and PV- related systems. Our validated viral-based approach can now be used to assess the behavioural effects and the underlying neurochemical mechanisms of chronic RXFP3 activation in other regions involved in anxiety-related circuitry, such as the amygdala, BNST, and the prefrontal cortex. 


\section{Conflict of Interest}

The authors declare that they have no conflict of interest.

This article is protected by copyright. All rights reserved. 


\section{References}

Adamec RE, McKay D. 1993. The effects of CRF and alpha-helical CRF on anxiety in normal and hypophysectomized rats. J Psychopharmacol. 7:346-354.

Adhikari A, Topiwala MA, Gordon JA. 2010. Synchronized activity between the ventral hippocampus and the medial prefrontal cortex during anxiety. Neuron. 65:257-269.

Adhikari A, Topiwala MA, Gordon JA. 2011. Single units in the medial prefrontal cortex with anxiety-related firing patterns are preferentially influenced by ventral hippocampal activity. Neuron. 71:898-910.

Albert-Gasco H, Garcia-Aviles A, Moustafa S, Sanchez-Sarasua S, Gundlach AL, Olucha-Bordonau FE, Sanchez-Perez AM. 2017. Central relaxin-3 receptor (RXFP3) activation increases ERK phosphorylation in septal cholinergic neurons and impairs spatial working memory. Brain Struct Funct. 222:449-463.

Aznar S, Qian ZX, Knudsen GM. 2004. Non-serotonergic dorsal and median raphe projection onto parvalbumin- and calbindin-containing neurons in hippocampus and septum. Neuroscience. 124:573-581.

Banerjee A, Shen P-J, Ma S, Bathgate RA, Gundlach AL. 2010. Swim stress excitation of nucleus incertus and rapid induction of relaxin-3 expression via CRF1 activation. Neuropharmacology. 58:145-155.

Bassant MH, Simon A, Poindessous-Jazat F, Csaba Z, Epelbaum J, Dournaud P. 2005. Medial septal GABAergic neurons express the somatostatin sst2A receptor: functional consequences on unit firing and hippocampal theta. J Neurosci. 25:2032-2041. 
Bathgate RAD, Samuel CS, Burazin TCD, Layfield S, Claasz AA, Reytomas IGT, Dawson NF, Zhao C, Bond C, Summers RJ. 2002. Human relaxin gene 3 (H3) and the equivalent mouse relaxin (M3) gene Novel members of the relaxin peptide family. J Biol Chem. 277:1148-1157.

Becker A, Grecksch G, Bernstein HG, Hollt V, Bogerts B. 1999. Social behaviour in rats lesioned with ibotenic acid in the hippocampus: quantitative and qualitative analysis. Psychopharmacology (Berl). 144:333-338.

Blasiak A, Blasiak T, Lewandowski MH, Hossain MA, Wade JD, Gundlach AL. 2013. Relaxin-3 innervation of the intergeniculate leaflet of the rat thalamus-neuronal tract-tracing and in vitro electrophysiological studies. Eur J Neurosci. 37:1284-1294.

Bremner JD, Narayan M, Staib LH, Southwick SM, McGlashan T, Charney DS. 1999. Neural correlates of memories of childhood sexual abuse in women with and without posttraumatic stress disorder. Am J Psychiatry. 156:1787-1795.

Buckmaster PS, Kunkel DD, Robbins RJ, Schwartzkroin PA. 1994. Somatostatin-immunoreactivity in the hippocampus of mouse, rat, guinea pig, and rabbit. Hippocampus. 4:167-180.

Burazin TCD, Bathgate RAD, Macris M, Layfield S, Gundlach AL, Tregear GW. 2002. Restricted, but abundant, expression of the novel rat gene-3 (R3) relaxin in the dorsal tegmental region of brain. J Neurochem. 82:1553-1557.

Cadogan AK, Kendall DA, Fink H, Marsden CA. 1994. Social interaction increases 5-HT release and cAMP efflux in the rat ventral hippocampus in vivo. Behav Pharmacol. 5:299-305.

Calhoon GG, Tye KM. 2015. Resolving the neural circuits of anxiety. Nat Neurosci. 18:1394-1404. 
Çalışkan G, Müller I, Semtner M, Winkelmann A, Raza AS, Hollnagel JO, Rösler A, Heinemann U, Stork O, Meier JC. 2016. Identification of parvalbumin interneurons as cellular substrate of fear memory persistence. Cereb Cortex. 26:2325-2340.

Cenquizca LA, Swanson LW. 2007. Spatial organization of direct hippocampal field CA1 axonal projections to the rest of the cerebral cortex. Brain Res Rev. 56:1-26.

Chaudhry FA, Reimer RJ, Bellocchio EE, Danbolt NC, Osen KK, Edwards RH, Storm-Mathisen J. 1998. The vesicular GABA transporter, vGAT, localizes to synaptic vesicles in sets of glycinergic as well as GABAergic neurons. J Neurosci. 18:9733-9750.

Dunn AJ, File SE. 1987. Corticotropin-releasing factor has an anxiogenic action in the social interaction test. Horm Behav. 21:193-202.

Engin E, Stellbrink J, Treit D, Dickson CT. 2008. Anxiolytic and antidepressant effects of intracerebroventricularly administered somatostatin: behavioral and neurophysiological evidence. Neuroscience. 157:666-676.

Engin E, Treit D. 2007. The role of hippocampus in anxiety: intracerebral infusion studies. Behav Pharmacol. 18:365-374.

Esclapez M, Houser CR. 1995. Somatostatin neurons are a subpopulation of GABA neurons in the rat dentate gyrus: evidence from colocalization of pre-prosomatostatin and glutamate decarboxylase messenger RNAs. Neuroscience. 64:339-355.

Fanselow MS, Dong, Hong-Wei. 2010. Are the dorsal and ventral hippocampus functionally distinct structures? Neuron. 65:7-19. 
Farooq U, Rajkumar R, Sukumaran S, Wu Y, Tan WH, Dawe GS. 2013. Corticotropin-releasing factor infusion into nucleus incertus suppresses medial prefrontal cortical activity and hippocampomedial prefrontal cortical long-term potentiation. Eur J Neurosci. 38:2516-2525.

Felix-Ortiz AC, Tye KM. 2014. Amygdala inputs to the ventral hippocampus bidirectionally modulate social behavior. J Neurosci. 34:586-595.

File SE, Kenny PJ, Cheeta S. 2000. The role of the dorsal hippocampal serotonergic and cholinergic systems in the modulation of anxiety. Pharmacol Biochem Behav 66:65-72.

Freund TF, Buzsaki G. 1996. Interneurons of the hippocampus. Hippocampus. 6:347-470.

Fuchs T, Jefferson SJ, Hooper A, Yee P, Maguire J, Luscher B. 2017. Disinhibition of somatostatinpositive GABAergic interneurons results in an anxiolytic and antidepressant-like brain state. Mol Psychiatry. 22:920-930.

Funck VR, Fracalossi MP, Vidigal APP, Beijamini V. 2018. Dorsal hippocampal galanin modulates anxiety-like behaviours in rats. Brain Res 1687:74-81.

Ganella DE, Callander GE, Ma S, Bye CR, Gundlach AL, Bathgate RAD. 2013. Modulation of feeding by chronic rAAV expression of a relaxin-3 peptide agonist in rat hypothalamus. Gene Ther. 20:703-716.

Gasbarri A, Sulli A, Packard MG. 1997. The dopaminergic mesencephalic projections to the hippocampal formation in the rat. Prog Neuropsychopharmacol Biol Psychiatry. 21:1-22.

Gomez AF, Barthel AL, Hofmann SG. 2018. Comparing the efficacy of benzodiazepines and serotonergic anti-depressants for adults with generalized anxiety disorder: a meta-analytic review. Expert Opin Pharmacother. 19:883-894. 
Goto M, Swanson LW, Canteras NS. 2001. Connections of the nucleus incertus. J Comp Neurol. 438:86-122.

Guilloux JP, Douillard-Guilloux G, Kota R, Wang X, Gardier AM, Martinowich K, Tseng GC, Lewis DA, Sibille E. 2012. Molecular evidence for BDNF- and GABA-related dysfunctions in the amygdala of female subjects with major depression. Mol Psychiatry. 17:1130-1142.

Gulyas AI, Hajos N, Katona I, Freund TF. 2003. Interneurons are the local targets of hippocampal inhibitory cells which project to the medial septum. Eur J Neurosci. 17:1861-1872.

Gunther A, Luczak V, Gruteser N, Abel T, Baumann A. 2018. HCN4 knockdown in dorsal hippocampus promotes anxiety-like behavior in mice. Genes Brain Behav doi: 10.1111/gbb.12550.

Haidar M, Guevremont G, Zhang C, Bathgate RAD, Timofeeva E, Smith CM, Gundlach AL. 2017. Relaxin-3 inputs target hippocampal interneurons and deletion of hilar relaxin-3 receptors in 'floxed-RXFP3' mice impairs spatial memory. Hippocampus. 27:529-546.

Hangya B, Borhegyi Z, Szilagyi N, Freund TF, Varga V. 2009. GABAergic neurons of the medial septum lead the hippocampal network during theta activity. J Neurosci. 29:8094-8102.

Herman JP, Cullinan WE, Young EA, Akil H, Watson SJ. 1992. Selective forebrain fiber tract lesions implicate ventral hippocampal structures in tonic regulation of paraventricular nucleus corticotropin-releasing hormone (CRH) and arginine vasopressin (AVP) mRNA expression. Brain Res. 592:228-238.

Huang Q, Timofeeva E, Richard D. 2006. Regulation of corticotropin-releasing factor and its types 1 and 2 receptors by leptin in rats subjected to treadmill running-induced stress. J Endocrinol. 191:179-188 
Jimenez JC, Su K, Goldberg AR, Luna VM, Biane JS, Ordek G, Zhou P, Ong SK, Wright MA, Zweifel L, et al. 2018. Anxiety cells in a hippocampal-hypothalamic circuit. Neuron. 97:670-683.

Kalueff A, Nutt DJ. 1996. Role of GABA in memory and anxiety. Depress Anxiety. 4:100-110.

Kalueff AV. 2007. Neurobiology of memory and anxiety: from genes to behavior. Neural Plasticity. 2007:78171

Kania A, Gugula A, Grabowiecka A, de Ávila C, Blasiak T, Rajfur Z, Lewandowski MH, Hess G, Timofeeva E, Gundlach AL, Blasiak A. 2017. Inhibition of oxytocin and vasopressin neuron activity in rat hypothalamic paraventricular nucleus by relaxin-3/RXFP3 signalling. J Physiol (Lond) 595: 3425-47.

Katsumaru T, Kosaka T, Heizmann CW, Hama K. 1988. Immunocytocheimcal study of GABAergic neurons containing the calcium-binging protein parvalbumin in the rat hippocampus. Exp Brain Res. 72: 347-362.

Kennedy DP, Adolphs R. 2012. The social brain in psychiatric and neurological disorders. Trends Cogn Sci. 16:559-572.

Kessler RC, Chiu WT, Demler O, Merikangas KR, Walters EE. 2005. Prevalence, severity, and comorbidity of 12-month DSM-IV disorders in the National comorbidity survey replication. Arch Gen Psychiatry. 62:617-627.

Kheirbek MA, Drew LJ, Burghardt NS, Costantini DO, Tannenholz L, Ahmari SE, Zeng H, Fenton AA, Hen R. 2013. Differential control of learning and anxiety along the dorso-ventral axis of the dentate gyrus. Neuron. 77:955-968.

This article is protected by copyright. All rights reserved. 
Kizawa H, Nishi K, Ishibashi Y, Harada M, Asano T, Ito Y, Suzuki N, Hinuma S, Fujisawa Y, Onda H, Nishimura O, Fujino M. 2003. Production of recombinant human relaxin 3 in AtT20 cells. Regul Peptides. 113:79-84.

Kjelstrup KG, Tuvnes FA, Steffenach H-A, Murison R, Moser EI, Moser M-B. 2002. Reduced fear expression after lesions of the ventral hippocampus. Proc Natl Acad Sci USA. 99:10825-10830.

Klausberger T, Magill PJ, Marton LF, Roberts JD, Cobden PM, Buzsaki G, Somogyi P. 2003. Brainstate- and cell-type-specific firing of hippocampal interneurons in vivo. Nature. 421:844-848.

Klausberger T, Marton LF, Baude A, Roberts JD, Magill PJ, Somogyi P. 2004. Spike timing of dendrite-targeting bistratified cells during hippocampal network oscillations in vivo. Nat Neurosci. 7:41-47.

Klausberger T, Somogyi P. 2008. Neuronal diversity and temporal dynamics: the unity of hippocampal circuit operations. Science. 321:53-57.

LeDoux J. 2003. Emotion circuits in the brain. Annu Rev Neurosci. 23:155-184.

Lenglos C, Mitra A, Guevremont G, Timofeeva E. 2013. Sex differences in the effects of chronic stress and food restriction on body weight gain and brain expression of CRF and relaxin-3 in rats. Genes Brain Behav. 12:370-387.

Lenglos C, Mitra A, Guèvremont G, Timofeeva E. 2014. Regulation of expression of relaxin-3 and its receptor RXFP3 in the brain of diet-induced obese rats. Neuropeptides. 48:119-322.

Lenze EJ, Wetherell JL. 2011. A lifespan view of anxiety disorders. Dialogues Clin Neurosci. 13:381.

Li Q, Bartley AF, Dobrunz LE. 2017. Endogenously released neuropeptide Y suppresses hippocampal short-term facilitation and is impaired by stress-induced anxiety. J Neurosci. 37:23-37.

This article is protected by copyright. All rights reserved. 
Liguz-Lecznar M, Urban-Ciecko J, Kossut M. 2016. Somatostatin and somatostatin-containing neurons in shaping neuronal activity and plasticity. Front Neural Circuits. 10:48.

Lin LC, Sibille E. 2013. Reduced brain somatostatin in mood disorders: a common pathophysiological substrate and drug target? Front Pharmacol. 4 .

Lin LC, Sibille E. 2015. Somatostatin, neuronal vulnerability and behavioral emotionality. Mol Psychiatry. 20:377-387.

Liu C, Eriste E, Sutton S, Chen J, Roland B, Kuei C, Farmer N, Jörnvall H, Sillard R, Lovenberg TW. 2003. Identification of relaxin-3/INSL7 as an endogenous ligand for the orphan G-proteincoupled receptor GPCR135. J Biol Chem. 278:50754-50764.

Lovett-Barron M, Kaifosh P, Kheirbek MA, Danielson N, Zaremba JD, Reardon TR, Turi GF, Hen R, Zemelman BV, Losonczy A. 2014. Dendritic inhibition in the hippocampus supports fear learning. Science. 343:857-863.

Ma S, Allocca G, Ong-Pålsson EK, Singleton CE, Hawkes D, McDougall SJ, Williams SJ, Bathgate RAD, Gundlach AL. 2017. Nucleus incertus promotes cortical desynchronization and behavioral arousal. Brain Struct Funct. 222:515-537.

Ma S, Blasiak A, Olucha-Bordonau FE, Verberne AJ, Gundlach AL. 2013. Heterogeneous responses of nucleus incertus neurons to corticotrophin-releasing factor and coherent activity with hippocampal theta rhythm in the rat. J Physiol. 591:3981-4001.

Ma S, Bonaventure P, Ferraro T, Shen P-J, Burazin TCD, Bathgate RAD, Liu C, Tregear GW, Sutton SW, Gundlach AL. 2007. Relaxin-3 in GABA projection neurons of nucleus incertus suggests widespread influence on forebrain circuits via G-protein-coupled receptor-135 in the rat. Neuroscience. 144:165-190. 
Ma S, Gundlach AL. 2015. Ascending control of arousal and motivation: role of nucleus incertus and its peptide neuromodulators in behavioural responses to stress. J Neuroendocrinol. 27:457-467.

Ma S, Olucha-Bordonau FE, Hossain MA, Lin F, Kuei C, Liu C, Wade JD, Sutton SW, Nuñez A, Gundlach AL. 2009. Modulation of hippocampal theta oscillations and spatial memory by relaxin-3 neurons of the nucleus incertus. Learn Mem. 16:730-742.

Ma S, Shen PJ, Sang Q, Lanciego JL, Gundlach AL. 2009. Distribution of relaxin-3 mRNA and immunoreactivity and RXFP3-binding sites in the brain of the macaque, Macaca fascicularis. Ann N Y Acad Sci. 1160:256-258.

Maccaferri G, McBain CJ. 1995. Passive propagation of LTD to stratum oriens-alveus inhibitory neurons modulates the temporoammonic input to the hippocampal CA1 region. Neuron. 15:137145.

MacMillan S, Szeszko PR, Moore GJ, Madden R, Lorch E, Ivey J, Banerjee SP, Rosenberg DR. 2003. Increased amygdala: hippocampal volume ratios associated with severity of anxiety in pediatric major depression. J Child Adolesc Psychopharmacol. 13:65-73.

Maren S, Fanselow, Michael S. 1995. Synaptic plasticity in the basolateral amygdala induced by hippocampal formation stimulation in vivo. J Neurosci. 15:7548-7564.

Marin O. 2015. Interneuron dysfunction in psychiatric disorders. Nat Rev Neurosci 13: 107-120.

Martínez-Bellver S, Cervera-Ferri A, Luque-García A, Martínez-Ricós J, Valverde-Navarro A, Bataller M, Guerrero J, Teruel-Marti V. 2017. Causal relationships between neurons of the nucleus incertus and the hippocampal theta activity in the rat. J Physiol. 595:1775-1792.

McCown TJ. 2006. Adeno-associated virus-mediated expression and constitutive secretion of galanin suppresses limbic seizure activity in vivo. Mol Ther. 14:63-68. 
McEown K, Treit D. 2013. $\alpha 2 \mathrm{GABA}_{\mathrm{A}}$ receptor sub-units in the ventral hippocampus and $\alpha 5 \mathrm{GABA}_{\mathrm{A}}$ receptor sub-units in the dorsal hippocampus mediate anxiety and fear memory. Neuroscience 252:169-177.

McNaughton N, Gray JA. 2000. Anxiolytic action on the behavioural inhibition system implies multiple types of arousal contribute to anxiety. J Affect Disord. 61:161-176.

McNaughton N, Kocsis B, Hajos M. 2007. Elicited hippocampal theta rhythm: a screen for anxiolytic and procognitive drugs through changes in hippocampal function? Behav Pharmacol. 18:329-346.

Merlo Pich E, Samanin, R. 1989. A two-compartment exploratory model to study anxiolytic/anxiogenic effects of drugs in the rat. Pharmacol Res. 21:595-602.

Nuss P. 2015. Anxiety disorders and GABA neurotransmission: a disturbance of modulation. Neuropsychiatr Dis Treat. 11:165-175.

O'Keefe J, Dostrovsky J. 1971. The hippocampus as a spatial map. Preliminary evidence from unit activity in the freely-moving rat. Brain Res. 34:171-175.

Okuyama T, Kitamura T, Roy DS, Itohara S, Tonegawa S. 2016. Ventral CA1 neurons store social memory. Science. 353:1536-1541.

Olucha-Bordonau FE, Teruel V, Barcia-González J, Ruiz-Torner A, Valverde-Navarro AA, Martínez-Soriano F. 2003. Cytoarchitecture and efferent projections of the nucleus incertus of the rat. J Comp Neurol. 464:62-97.

Padilla-Coreano NB, Pierce GM, Blackman DR, Hardin WD, Garcia-Garcia AL, Spellman TJ, Gordon JA. 2016. Direct ventral hippocampal-prefrontal input is required for anxiety-related neural activity and behavior. Neuron. 4:857-866.

Paxinos G, Watson C. 2006. The Rat Brain in Stereotaxic Coordinates. Academic Press, New York. 
Pentkowski NS, Blanchard DC, Lever C, Litvin Y, Blanchard RJ. 2006. Effects of lesions to the dorsal and ventral hippocampus on defensive behaviors in rats. Eur J Neurosci. 23:2185-2196.

Pentkowski NS, Litvin Y, Blanchard DC, Vasconcellos A, King LB, Blanchard RJ. 2009. Effects of acidic-astressin and ovine-CRF microinfusions into the ventral hippocampus on defensive behaviors in rats. Horm Behav. 56:35-43.

Pickel VM, Segal M, Bloom FE. 1974. A radioautographic study of the efferent pathways of the nucleus locus coeruleus. J Comp Neurol. 155:15-42.

Radulovic J, Ruhmann A, Liepold T, Spiess J. 1999. Modulation of learning and anxiety by corticotropin-releasing factor (CRF) and stress: differential roles of CRF receptors 1 and 2. J Neurosci. 19:5016-5025.

Rezvanfard M, Zarrindast MR, Bina P. 2009. Role of ventral hippocampal GABA(A) and NMDA receptors in the anxiolytic effect of carbamazepine in rats using the elevated plus maze test. Pharmacology. 84:356-366.

Ribeiro-Barbosa ER, Canteras NS, Cezario AF, Blanchard RJ, Blanchard DC. 2005. An alternative experimental procedure for studying predator-related defensive responses. Neurosci Biobehav Rev. 29:1255-1263.

Richardson MP, Strange BA, Dolan RJ. 2004. Encoding of emotional memories depends on amygdala and hippocampus and their interactions. Nat Neurosci. 7:278-285.

Ryan PJ, Buchler E, Shabanpoor F, Hossain MA, Wade JD, Lawrence AJ, Gundlach AL. 2013. Central relaxin-3 receptor (RXFP3) activation decreases anxiety- and depressive-like behaviours in the rat. Behav Brain Res. 244:142-151. 
Ryan PJ, Kastman HE, Krstew EV, Rosengren KJ, Hossain MA, Churilov L, Wade JD, Gundlach AL, Lawrence AJ. 2013. Relaxin-3/RXFP3 system regulates alcohol-seeking. Proc Natl Acad Sci USA. 110:20789-20794.

Ryan PJ, Ma S, Olucha-Bordonau FE, Gundlach AL. 2011. Nucleus incertus - an emerging modulatory role in arousal, stress and memory. Neurosci Biobehav Rev. 35:1326-1341.

Sams-Dodd F, Lipska BK, Weinberger DR. 1997. Neonatal lesions of the rat ventral hippocampus result in hyperlocomotion and deficits in social behaviour in adulthood. Psychopharmacology (Berl). 132:303-310.

Schindler M, Sellers LA, Humphrey PP, Emson PC. 1997. Immunohistochemical localization of the somatostatin SST2(A) receptor in the rat brain and spinal cord. Neuroscience. 76:225-240.

Schmid LC, Mittag M, Poll S, Steffen J, Wagner J, Geis H-R, Schwarz I, Schmidt B, Schwarz MK, Remy S, Fuhrmann M. 2016. Dysfunction of somatostatin-positive interneurons associated with memory deficits in an Alzheimer's disease model. Neuron. 92:114-125.

Scoville WB, Milner B. 1957. Loss of recent memory after bilateral hippocampal lesions. J Neurol Neurosurg Psychiatry. 20:11-21.

Siegmund A, Köster L, Meves AM, Plag J, Stoy M, Ströhle A. 2011. Stress hormones during flooding therapy and their relationship to therapy outcome in patients with panic disorder and agoraphobia. J Psychiatr Res. 45:339-346.

Smith CM, Shen PJ, Banerjee A, Bonaventure P, Ma S, Bathgate RAD, Sutton SW, Gundlach AL. 2010. Distribution of relaxin-3 and RXFP3 within arousal, stress, affective, and cognitive circuits of mouse brain. J Comp Neurol. 518:4016-4045. 
Smith CM, Blasiak A, Ganella DE, Chua BE, Layfield SL, Bathgate RAD, Gundlach AL. 2013. Viralmediated delivery of an RXFP3 agonist into brain promotes arousal in mice. Ital J Anat Embryol. 118:42-46.

Solati J, Zarrindast MR, Salari AA. 2010. Dorsal hippocampal opioidergic system modulates anxietylike behaviors in adult male Wistar rats. Psychiatry Clin Neurosci 64:634-641.

Squire LR. 1992. Memory and the hippocampus: a synthesis from findings with rats, monkeys, and humans. Psychol Rev. 99:195-231.

Stefanelli T, Bertollini C, Luscher C, Muller D, Mendez P. 2016. Hippocampal somatostatin interneurons control the size of neuronal memory ensembles. Neuron. 89:1074-1085.

Stroh T, Kreienkamp HJ, Beaudet A. 1999. Immunohistochemical distribution of the somatostatin receptor subtype 5 in the adult rat brain: predominant expression in the basal forebrain. $\mathrm{J}$ Comp Neurol. 412:69-82.

Sun XR, Zhang H, Zhao HT, Ji MH, Li HH, Wu J, Li KY, Yang JJ. 2016. Amelioration of oxidative stress-induced phenotype loss of parvalbumin interneurons might contribute to the beneficial effects of environmental enrichment in a rat model of post-traumatic stress disorder. Behav Brain Res. 312:84-92.

Sutton SW, Bonaventure P, Kuei C, Roland B, Chen J, Nepomuceno D, Lovenberg TW, Liu C. 2005. Distribution of G-protein-coupled receptor (GPCR) 135 binding sites and receptor mRNA in the rat brain suggests a role for relaxin-3 in neuroendocrine and sensory processing. Neuroendocrinology. 80:298-307.

Sztainberg Y, Kuperman Y, Justice N, Chen A. 2011. An anxiolytic role for CRF receptor type 1 in the globus pallidus. J Neurosci. 31:17416-17424. 
Tanaka M. 2010. Relaxin-3/insulin-like peptide 7, a neuropeptide involved in the stress response and food intake. FEBS J. 277:4990-4997.

Tanaka M, Iijima N, Miyamoto Y, Fukusumi S, Itoh Y, Ozawa H, Ibata Y. 2005. Neurons expressing relaxin 3/INSL 7 in the nucleus incertus respond to stress. Eur J Neurosci. 21:1659-1670.

Urban-Ciecko J, Barth AL. 2016. Somatostatin-expressing neurons in cortical networks. Nat Rev Neurosci. 17:401-409.

Walf AA, Frye CA. 2007. The use of the elevated plus maze as an assay of anxiety-related behavior in rodents. Nat Protoc. 2:322-328.

Walker AW, Smith CM, Chua BE, Krstew EV, Zhang C, Gundlach AL, Lawrence AJ. 2015. Relaxin3 receptor (RXFP3) signalling mediates stress-related alcohol preference in mice. PLoS One. 10:e0122504.

Walker LC, Kastman HE, Koeleman JA, Smith CM, Perry CJ, Krstew EV, Gundlach AL, Lawrence AJ. 2017. Nucleus incertus corticotrophin-releasing factor 1 receptor signalling regulates alcohol seeking in rats. Addict Biol. 22:1641-1654.

Weeden CS, Roberts JM, Kamm AM, Kesner RP. 2014. The role of the ventral dentate gyrus in anxiety-based behaviors. Neurobiol Learn Mem. 118:143-149.

Wik G, Fredrikson M, Ericson K, Eriksson L, Stone-Elander S, Greitz T. 1993. A functional cerebral response to frightening visual stimulation. Psychiatry Res. 50:15-24.

Wilkinson TN, Speed TP, Tregear GW, Bathgate RAD. 2005. Evolution of the relaxin-like peptide family. BMC Evol Biol. 5:14. 
Winkelmann A, Maggio N, Eller J, Caliskan G, Semtner M, Häussler U, Jüttner R, Dugladze T, Smolinsky B, Kowalczyk S, et al. 2014. Changes in neural network homeostasis trigger neuropsychiatric symptoms. J Clin Invest. 124:696-711.

Wöhr M, Orduz D, Gregory P, Moreno H, Khan U, Vörckel KJ, Wolfer DP, Welzl H, Gall D, Schiffmann SN, et al. 2015. Lack of parvalbumin in mice leads to behavioral deficits relevant to all human autism core symptoms and related neural morphofunctional abnormalities. Transl Psychiatry. 5:e525.

Yeung M, Engin E, Treit D. 2011. Anxiolytic-like effects of somatostatin isoforms SST 14 and SST 28 in two animal models (Rattus norvegicus) after intra-amygdalar and intra-septal microinfusions. Psychopharmacology (Berl). 216:557-567.

Yeung M, Treit D. 2012. The anxiolytic effects of somatostatin following intra-septal and intraamygdalar microinfusions are reversed by the selective sst2 antagonist PRL2903. Pharmacol Biochem Behav. 101:88-92.

Yuan M, Meyer T, Benkowitz C, Savanthrapadian S, Ansel-Bollepalli L, Foggetti A, Wulff P, Alcami P, Elgueta C, Bartos M. 2017. Somatostatin-positive interneurons in the dentate gyrus of mice provide local- and long-range septal synaptic inhibition. Elife. 6 e21105.

Zou D, Chen L, Deng D, Jiang D, Dong F, McSweeney C, Zhou Y, Liu L, Chen G, Wu Y, Mao Y. 2016. DREADD in parvalbumin interneurons of the dentate gyrus modulates anxiety, social interaction and memory extinction. Curr Mol Med. 16:91-102. 


\section{Figure Legends}

Figure 1. Schematics of adeno-associated viral (AAV) vectors used to transduce neurons in vHip. (A) Control viral vector construct: $\mathrm{AAV}^{1 / 2}$-sCAG-eGFP, in which the AAV serotype 2 and the coding sequence of eGFP was packaged into a rAAV mosaic serotype $1 / 2$ capsid; resulting in cellular eGFP as the vector product. (B) Agonist viral vector constructs: AAV ${ }^{1 / 2}$-FIB-R3I5 and AAV ${ }^{1 / 2}$-FIB-R3I5IRES-eGFP, in which the AAV serotype 2 and the coding sequence of FIB-R3/I5 or FIB-R3I5-IRESeGFP was packaged into a rAAV mosaic serotype $1 / 2$ capsid. The resultant vector products were secreted R3/I5, and secreted R3/I5 plus cellular eGFP, respectively.

Figure 2. Distribution of viral vectors within the vHip of rats subjected to behavioural analysis. (A) Transduction of vHip neurons with $\mathrm{AAV}^{1 / 2}$-sCAG-GFP and $\mathrm{AAV}^{1 / 2}$-FIB-R3I5-IRES-eGFP. Fluorescence microscopy images of eGFP expression in a representative rat from the vHip-eGFP and vHip-R3/I5 groups. (B) Coronal sections of the vHip depicting histologically-verified placements of virus injections in the vHip-eGFP control group $(n=11)$ and $(\mathbf{C})$ vHip-R3/I5 group $(n=7)$. Representations of the hippocampus are modified from (Paxinos and Watson 2006).

Figure 3. Distribution of RXFP3 mRNA in vHip and co-expression with vGAT, SST and PV mRNA. (A, B) Distribution of RXFP3 and vGAT mRNA in the CA1 and DG, respectively. Lowpower overview images (left) and high-power images (boxed areas) of RXFP3 (green) and vGAT mRNA (red), and a merged image with DAPI staining of neurons located in (A) the CA1 oriens layer and in (B) the DG polymorph layer. Arrowheads indicate examples of double-labelled neurons that coexpress vGAT and RXFP3 mRNA. (C, D) Low-power overview images (left) and high-power images (boxed areas) of RXFP3 (green) and SST mRNA (red), and a merged image with DAPI staining in neurons located in (C) the CA3 oriens layer and in (D) the DG polymorph layer. Arrowheads indicate 
examples of double-labelled neurons that co-express SST and RXFP3 mRNA. Open arrowheads indicate an example of a labelled neuron that expresses SST mRNA, but does not express RXFP3 mRNA. (E) Low-power overview image (left) and high-power images (boxed area) of RXFP3 (green), PV (red) mRNA, and a merged image with SST (white) and DAPI staining in neurons located in the CA3. Arrowheads indicate an example of a neuron that co-expresses RXFP3, PV and SST mRNA, and open arrowheads indicate a neuron that expresses RXFP3 mRNA, but does not express PV mRNA. Scale bars, $200 \mu \mathrm{m}$ and $20 \mu \mathrm{m}$. Abbreviations: alv, alveus; cp, cerebral peduncle; Gr, granule cell layer; Mo, molecular layer; Or, oriens layer; Po, polymorphic layer; Py, pyramidal layer; Rad, radiatum layer.

Figure 4. Co-localization of RXFP3, SST, and PV mRNA in the CA1 and CA3 vHip subfields. Percentage co-localization of RXFP3, SST, and PV mRNA was assessed at matching rostro-caudal levels of the CA1 and CA3 subfields of vHip. Data were collected from 2-3 naïve rats. The percentage co-localization of RXFP3, SST, and PV mRNA was assessed at matching rostro-caudal levels of the CA1 and CA3 subfields of vHip. Data were collected from 2-3 naïve rats. Three analogous sections that contain the vHip were delineated into CA1 and CA3 regions (as defined in the Rat Brain Atlas, (Paxinos and Watson, 2006)). Each region was imaged and neurons were counted using FIJI software for mRNA expression in each layer within each region.

Figure 5. Distribution of relaxin-3-immunoreactive nerve fibres and SST- and PVimmunoreactive neurons in the rat vHip. (A) Mosaic confocal images ( $\times 20$ magnification) of rat DG, illustrating relaxin-3 immunoreactive fibres (green) in close vicinity of SST-immunoreactive neurons (red). Boxed area in $A$ is shown on the right and illustrates ( $\times 63$ magnification) SSTimmunoreactive neurons (red) in the DG and relaxin-3 fibres (green) represented as three-dimensional 
orthogonal view in 3 planes $(\mathrm{y} / \mathrm{x}, \mathrm{x} / \mathrm{z}, \mathrm{y} / \mathrm{z})$. (B) Mosaic confocal images $(\times 20$ magnification) of rat CA1, illustrating relaxin-3 immunoreactive fibres (green) in close vicinity of PV-immunoreactive neurons (red). Boxed area in B is shown on the right and illustrates ( $\times 63$ magnification) PV-immunoreactive neurons (red) in the CA1 and relaxin-3 fibres (green) represented as three-dimensional orthogonal view in 3 planes $(\mathrm{y} / \mathrm{x}, \mathrm{x} / \mathrm{z}, \mathrm{y} / \mathrm{z})$. Scale bars, $200 \mu \mathrm{m}$ and $10 \mu \mathrm{m}$.

Figure 6. Effect of chronic RXFP3 activation in vHip on performance in the elevated plus maze and light-dark box. (A) Compared with control ( $n=11$; open circles), vHip-R3/I5 rats ( $n=7$; closed circles) spent significantly less time, travelled less distance, and made fewer entries in the open arms of the EPM. Consistent with this, they spent more time in the closed arms of the EPM, travelled less distance in the closed arms, and there was no difference in the number of entries into the closed arms of the EPM. (B) Compared with control, vHip-R3/I5 rats spent less time and travelled less distance in the light zone of the LDB. No differences were observed in the number of light zone entries, or distance travelled in the dark zone. Data is represented as mean \pm SEM. *, $p \leq 0.05 ; * *, p \leq 0.01 ; * * *$, $p \leq 0.001 ; n s$, not significant.

Figure 7. Effect of chronic RXFP3 activation in vHip on performance in the large open-field. In the large open-field test, there was no significant differences observed between the control vHip-eGFP group ( $\mathrm{n}=11$; open circles) and the vHip-R3/I5 group ( $\mathrm{n}=7$; closed circles) in the time spent in the centre or in the periphery, the number of entries into the periphery, the distance travelled in the centre or periphery, or in total distance travelled. Data is represented as mean \pm SEM. $n s$, not significant.

Figure 8. Chronic RXFP3 activation in vHip reduced social interaction with a conspecific stranger rat. Compared with control $(\mathrm{n}=11$; open circles), vHip-R3/I5 rats $(\mathrm{n}=7$; closed circles) 
spent significantly less time engaging in social approach and leave, follow, and sniff with a conspecific, sex and age-matched, stranger rat. Reduction in these social behaviours was accompanied with increased passive contact (i.e. less contact initiation). Data is represented as mean \pm SEM. *, $p \leq$ $0.05 ; * *, p \leq 0.01 ; n s$, not significant. 


\section{University Library}

\section{- M M N E R VA A gateway to Melbourne's research publications}

Minerva Access is the Institutional Repository of The University of Melbourne

Author/s:

Rytova, V;Ganella, DE;Hawkes, D;Bathgate, RAD;Ma, S;Gundlach, AL

Title:

Chronic activation of the relaxin-3 receptor on GABA neurons in rat ventral hippocampus promotes anxiety and social avoidance

Date:

2019-10-01

Citation:

Rytova, V., Ganella, D. E., Hawkes, D., Bathgate, R. A. D., Ma, S. \& Gundlach, A. L. (2019). Chronic activation of the relaxin-3 receptor on GABA neurons in rat ventral hippocampus promotes anxiety and social avoidance. HIPPOCAMPUS, 29 (10), pp.905-920. https:// doi.org/10.1002/hipo.23089.

Persistent Link:

http://hdl.handle.net/11343/285600 